\title{
A retórica da pronunciação na performance instrumental: modelos suplementares para a articulação musical
}

\author{
William Teixeira \\ Universidade Federal de Mato Grosso do Sul \\ william.teixeira@ufms.br
}

\begin{abstract}
Resumo: Este artigo discute sobre modelos de agrupamento melódico, compreendendo a implicação de cada um deles para a performance musical e partindo da própria performance como uma produtora de questões e conclusões para essa reflexão. Isso porque a necessidade de se conectar sons no discurso musical e, portanto, de separá-los, é uma inevitável consequência, por um lado, da limitação dos meios instrumentais e vocais e, por outro, da própria disposição da música no tempo. Para tanto, serão analisadas peças curtas dos compositores György Kurtág (Az hit..., 1963/2007), B. A. Zimmermann (4 Pequenos estudos, 1970) e Silvio Ferraz (Partita-passagem, 2019), de maneira a apresentar uma visão ampla e, ainda assim, objetiva de novas demandas de agrupamento temporal.
\end{abstract}

Palavras-chave: Performance musical, Música contemporânea, Fraseologia musical, Agrupamentos musicais, Fluxo de energia.

\section{The Rhetoric of Pronunciation in Instrumental Performance: supplementary models for musical articulation}

\begin{abstract}
This paper discusses models for melodic grouping, understanding the implication of each one for musical performance and starting from the performance itself as a producer of questions and conclusions for this reflection. This is because the necessity to connect sounds in musical discourse and, therefore, to separate them, is an inevitable consequence, on the one hand, of the limitation of instrumental and vocal means and, on the other, of the very disposition of music in time. Short pieces by composers (Az hit..., 1963/2007), B. A. Zimmermann (4 Short Studies, 1970) and Silvio Ferraz (Partitapassagem, 2019) will be analysed in order to present a broad and yet objective view of new demands of temporal grouping.
\end{abstract}

Keywords: Musical Performance, Contemporary Music, Musical Phrase, Melodic Grouping, Energy Flow.

\section{Nota introdutória: teoria como analogia}

A ligação entre a performance instrumental e a voz, seja falada ou cantada, se torna nítida nas primeiras aulas de qualquer estudante de música. Desde as primeiras sílabas aprendidas por um instrumentista de sopro, até o contorno dinâmico que se

O presente artigo desenvolve o trabalho apresentado no V Encontro Internacional de Teoria e Análise Musical, EITAM5 (TEIXEIRA, 2019, p. 319-332). 
aprende a dar a uma frase musical, a busca por modelos verbais é incessante. Essa busca se intensifica quando o estudo musicológico demonstra que mais do que uma coincidência expressiva, a ligação entre o discurso musical e o discurso verbal foi de fato um diálogo decisivo para a ascensão do primeiro a partir da música barroca. Foi a descoberta desse evento que motivou uma primeira revisão bibliográfica das principais menções à articulação musical dentro do escopo da retórica musical no barroco alemão, identificando correspondências bastante acentuadas entre a consideração que os tratadistas faziam da constituição da frase musical em relação à frase verbal, buscando desde aquele momento quais seriam as aplicações práticas desse conhecimento (TEIXEIRA; NOGUEIRA, 2011). Mas de maneira ainda mais marcante, a correspondência entre microestruturas de identificação do ataque de som com fonemas silábicos vogais e consonantais, prática essa inserida dentro da última parte da retórica clássica, a pronuntiatio, se mostrou uma fonte riquíssima de ideias musicais, ainda que parecesse oculta no abismo deixado pela ausência de uma prática comum.

Por mais incertas que pareçam as aplicações dessa pronunciação na performance da música barroca, ela já elucida e aponta direções interpretativas claras, ainda que não definitivas. No entanto, essa conexão deixou em aberto a questão sobre se haveria traços dessa relação no repertório posterior e, em especial, no repertório contemporâneo, onde a performance se complexifica por uma falta de indicadores harmônicos que ofereçam direções para o fraseado musical. Essa questão tem permeado trabalhos posteriores, mesmo que de maneira aparentemente periférica (TEIXEIRA; FERRAZ, 2013; TEIXEIRA; FERRAZ, 2017). Ainda que o percurso dessa questão de pesquisa não tenha cessado, a volta àqueles caminhos relacionados diretamente com a pronunciação verbal voltou a se mostrar como uma hipótese relevante diante de alguns casos do repertorio recente.

Como foi dito, a relação da frase musical com a frase verbal carrega consigo uma potente condição, de difícil realização, mas que, tão logo seja assimilada, possui ainda mais dificultosa superação. Desde um pueril "Brilha, brilha, estrelinha", somos ensinados a construir inflexões dinâmicas e agógicas para aquela sequencia de notas que à adeque ao modelo verbal, especialmente com a frase cantada e suas correspondentes pontuações, estabelecendo tipos de sílabas tônicas às quais se direcione o apoio físico da performance. A analogia da frase, não por acaso, é muito adequada à interpretação de 
boa parte do repertório ocidental, principalmente dos séculos XVIII e XIX, não apenas pela origem retórica da música instrumental, mas também porque esse modelo fora estabelecido por importantes tratados de composição, em especial, no que tange à terminologia até hoje adotada, o Tratado de Composição Musical (Versuch einer Anleitung zur Composition), publicado pelo teórico alemão Heinrich Christoph Koch ao redor dos anos de 1790, cujo título do terceiro volume já nos resume bem o conteúdo nesse tema: "Sobre as regras mecânicas da melodia: Da combinação das partes melódicas ou da estrutura dos períodos". Desse tratado advém boa parte da compreensão até hoje reproduzida sobre a frase musical, desde aquela do grande estudioso de Koch do final do século XIX, Hugo Riemann, chegando à sua retomada por Schoenberg e, no Brasil por Esther Scliar, além de Fred Lerdahl e Jackendoff e sua formalização na teoria dos agrupamentos sonoros. Entretanto, já em Riemann o vínculo de dependência se fez tão notável, que Herman Keller (1973, p. 9) afirmava que sua proposta havia subsidiado toda uma geração de editores musicais, que modificaram toda a notação da música pré-romântica para adequá-la a este modelo unívoco, o que dificilmente seria superado. O corolário do percurso de Riemann a Lerdhal e Jackedoff é bem conhecido, entretanto se faz precisamente sintetizado e sistematizado nas quatro categorias sumarizadas por Caio Barros em sua dissertação de mestrado, que reúne e revisa as mencionadas abordagens, sendo essas quatro categorias:

1. Discrição: Os agrupamentos sonoros são elementos discretos, segmentos que possuem início e fim. [...] 2. Contenção: Agrupamentos de maior duração contam agrupamentos de menor duração em uma estrutura em diferentes níveis. [...] 3. Recursividade: Os níveis são também recursivos, isto é, podem ser replicados indefinidamente sob as mesmas regras. 4. Processualidade: Os agrupamentos são formados na escuta em tempo real. (BARROS, 2013, p. 19)

Do paradigma da frase emergem não apenas concepções teóricas e composicionais, mas, naquilo que interessa primordialmente a este trabalho, toda uma concepção de performance musical, que não apenas condiciona as escolhas musicais do intérprete, mas que, em última instância, é capaz de formar sua própria técnica instrumental. Isso significa que esse paradigma e tais categorias há pouco definidas formam toda a concepção que um instrumentista de cordas, por exemplo, adquiri e passa a possuir na utilização de seu arco, com sua proveniente divisão, aplicação de 
peso e escolha de regiões e sentidos de ataque. Isso implica em todo um modelo de respiração que formará as capacidades físicas também de um instrumentista de sopro que, ainda que supere tais limitações por meio da respiração contínua, preservará um senso de direção e apoio estritamente ligados à noção de frase. Esse paradigma irá influenciar toda a concepção de dedilhados de um pianista ou de um violonista e mesmo a manulação de um percussionista. Disso posto de maneira abrangente, o que se conclui, preliminarmente, é que a frase musical, como analogia que é, possui a capacidade de formar e estruturar não apenas a música, mas o próprio músico.

Voltando à dissertação de Caio Barros (2013), sua qualidade reside não apenas na sistematização feita dos postulados teóricos sobre a frase musical, mas principalmente na análise realizada dos pressupostos epistemológicos que subjazem tais abordagens. Barros identifica uma direção comum nos modelos do século XX de se legitimarem cientificamente, via de regra se inscrevendo em campos como a cognição musical, se afastando assim do objetivo artístico-didático que os tratados pioneiros possuíam no âmbito da composição. Esse esforço para se "purificar de devaneios teóricos abstratos" a teoria musical, faz com que a teoria adote um modelo "essencialista" (BARROS, 2013, p. 24-25) onde a representação teórica objetiva sua superação enquanto modelo analógico e passa a se confundir com a própria Verdade, isto é, outorgando a si o papel de uma teoria geral ou final, já que tais teorias apontam a frase musical e o agrupamento sonoro não apenas como possibilidades, mas como necessidades cognitivas humanas.

É por isso que se faz primeiramente necessário se recuperar a conotação analógica da teoria musical. $\mathrm{O}$ próprio termo grego original, analogein, acrescenta à raiz logos o prefixo ana, que denota uma sucessão. Desse modo, a analogia consiste exatamente em uma lógica que sucede ou supera a lógica ordinária de um conceito ou realidade, fazendo uso de uma contiguidade predicativa para expor aspectos mais complexos em uma realidade mais simples, em uma espécie de transdução conceitual. Desse modo, parece importante que ao se propor uma leitura fique clara a pretensão de tal teoria, especialmente em um contexto ligado à prática, de maneira que essa leitura não pareça exclusiva ou fatalmente normativa (TORRANCE, 2005).

Foi exatamente dentro dessa compreensão que tratadistas antigos concebiam sua abordagem fraseológica como um modelo teórico para a sucessividade melódica. Aliás, 
desde Aristóxenes, o próprio vocábulo melos denotava não uma sucessão de sons ou notas, mas a parte de um todo. O melos da mousiké poderia denotar qualquer parte da ode às musas, consistindo assim em uma melodia. $\mathrm{O}$ mesmo termo era utilizado para se denominar partes de um corpo, partes essas que deveriam ser ligadas por juntas, por sua vez, no grego, harmos, de onde vem harmonia. Sendo assim, a compreensão de uma certa parte do discurso musical que se organiza a partir da sucessividade de sons interessa na medida de sua conexão com outras partes, constituindo um todo musical. Mesmo no alemão, o termo utilizado nos tratados antigos era Satz, termo polissêmico traduzido de Schoenberg como sentença, mas que em um primeiro momento dentro do idioma germânico denotava a realização polifônica de um baixo cifrado. A polissemia é tanta que em meados do século do século XIX, Hauptsatz denomina tanto uma frase principal, quanto um grupo temático principal, passando a denominar por Riemann até mesmo as funções harmônicas primárias. Sendo assim, o termo se referia mais amplamente às partes de uma configuração musical geral, razão pela qual o termo foi também traduzido ao inglês, posterior e questionavelmente, por textura. (DRABKIN; PFINGSTEN, 2001).

Esse excurso etimológico não tem outro objetivo que não apontar a profusão de analogias possíveis para a partição melódica ou sucessiva já no nascedouro da concepção teórica da frase musical, exemplificando que apesar de historicamente fundamental, esse paradigma está longe de ser essencial à estruturação musical e, muito menos, à constituição cognitiva da percepção humana. Seria interessante se pensar, assim, em algumas outras possibilidades de operação analógica da sucessão melódica ou, para usar a terminologia de Lerdahl e Jackendoff, para operar a sucessividade de singularidades sonoras, enfatizando sua consequência intrínseca à performance musical, o que acarretaria a expansão do conceito de singularidade sonora para uma singularidade gestual.

Alguns exemplos alternativos poderiam ser encontrados ainda mesmo no discurso verbal, exemplos esses que extrapolam os limites da frase gramaticalmente bem estruturada do ponto de vista formal. Poderíamos recordar o trabalho a partir de James Joyce por Berio em um certo processo de aliterações e permutações (MENEZES, 2015) e, mesmo no Brasil, o trabalho a partir dos poetas concretos por Gilberto Mendes que interpenetra sílabas, ocultando a linearidade das frases verbal e musical (SILVA, 2014). Dessa forma, serão expostos nas seções a seguir três exemplos de peças recentes do 
repertório para violoncelo solo que demandam atitudes diversas para com a articulação do discurso musical. $\mathrm{O}$ que une as três além do instrumento para o qual se destinam não é nada mais do que o fato de terem integrado um mesmo repertório tocado por este autor $^{1}$. Igualmente, os modelos de articulação e agrupamento dos quais foram extraídos caminhos diversos para a estruturação da performance eram apenas aqueles que já habitavam o imaginário deste pesquisador-performer e que auxiliaram no processo de fuga do modelo estudado academicamente que parecia afastar tais peças de uma interpretação efetiva.

\section{György Kurtág, $A z$ hit...}

O primeiro exemplo (Fig. 1) é a peça $A z$ hit..., de György Kurtág, uma versão para violoncelo solo do último movimento de sua suíte Os sermões de Peter Bornemisza, Op. 7, para soprano e piano. A versão para violoncelo também traz a letra original na partitura, como é o caso de outras peças instrumentais de Kurtág.

Figura 1 - György Kurtág, Az hit..., linhas 1 e 2.
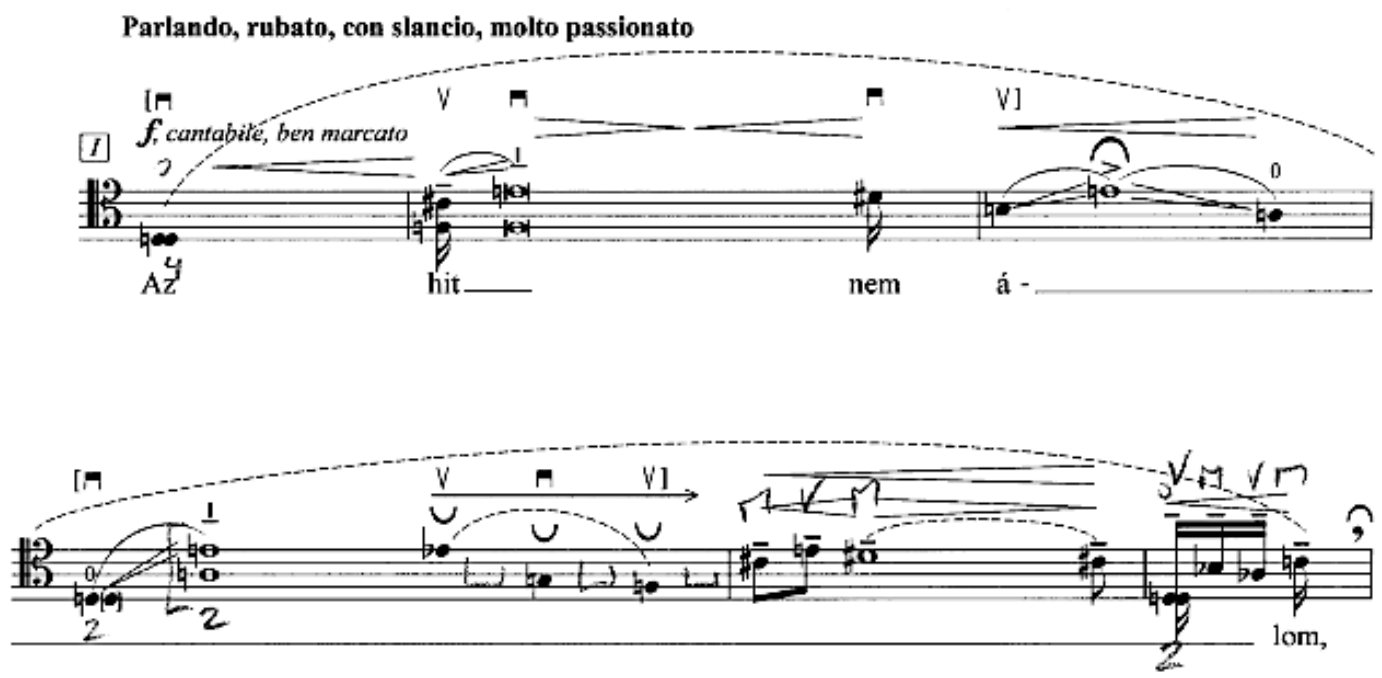

Fonte: Editio Musica Budapest, 2007.

\footnotetext{
${ }^{1}$ Recital Cello Mythos (série de concertos de violoncelo solo). Repertório: J. S. Bach, Suite n. 4, em Mi bemol Maior; B. A. Zimmermann, 4 Pequenos estudos; Roberto Victório, Aztlan; Silvio Ferraz, Partita n. 3 (estreia da obra); G. Kurtág, Az hit; Rogério Costa, Desdobramentos. Concertos realizados em São Paulo (Capela da Universidade Presbiteriana Mackenzie, 22 abr. 2019), São Carlos (UFSCAR, 23 abr. 2019), Coxim (UFMS, 17 maio 2019) e Ponta Porã (UFMS, 24 maio 2019).
} 
Não apenas uma conexão com a fala é demandada pela indicação de parlando, mas a maneira de articular a linha contém notações advindas da escrita do cantochão que indicam uma escrita proporcional ao invés de métrica (SZENDY, 1990). Essa irregularidade torna necessário um outro árbitro para as durações e, à semelhança do cantochão, se torna o texto o responsável por tais decisões, ainda que não seja efetivamente pronunciado, além de servir como modelo para a articulações dos ataques internos correspondentes aos fonemas das silabas escritas. As inflexões internas do agrupamento também são descritas por minuciosas movimentações dinâmicas, mas a semântica linguística, ainda que não venha a ser objeto da escuta, irá orientar uma ênfase afetiva, sobretudo em certas palavras-chave, que são eixos discursivos da peça (WILSON, 2003). Uma tradução aproximada do texto auxilia a compreensão dessa abordagem:

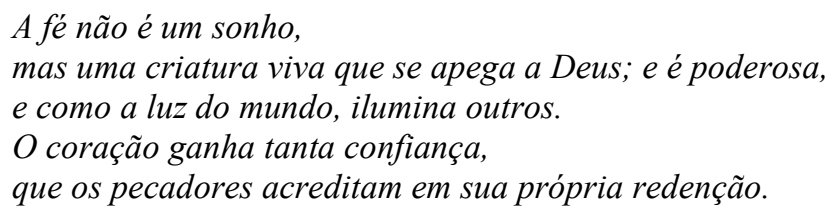

A própria versificação do texto já modifica consideravelmente a noção de segmentação em frases que a partitura mantém obscura devido às suas muitas notações. Algumas direções afetivas ficam mais claras, como o caráter resoluto do verso 1 , a grandiosidade do verso 2, a luminosidade do verso 3, novamente o senso resoluto do verso 4 e, finalmente, a paixão contrita do verso 5. Além disso, conforme sugere Wilson (2003), a palavra "pecado", assim como "pecadores", é uma ideia chave em toda a suíte original e, na verdade, em toda a obra de Kurtág. A peça, que de tantas notações, não possui nenhuma indicação de dinâmica, alcança um clímax melismático sobre a palavra bünös [pecadores] (Fig. 2).

Essas microarticulações, no entanto, não seriam explicitadas pelas relações entre alturas tão somente, de maneira que adentra o trabalho composicional em um contexto pós-serial o emprego de outros recursos que indiquem a direção do fluxo melódico, já que sua dimensão temporal supera as possibilidades de duração de uma frase verbal comum ou mesmo de uma frase musical mais comum 
Figura 2 - György Kurtág, Az hit..., linha 7.

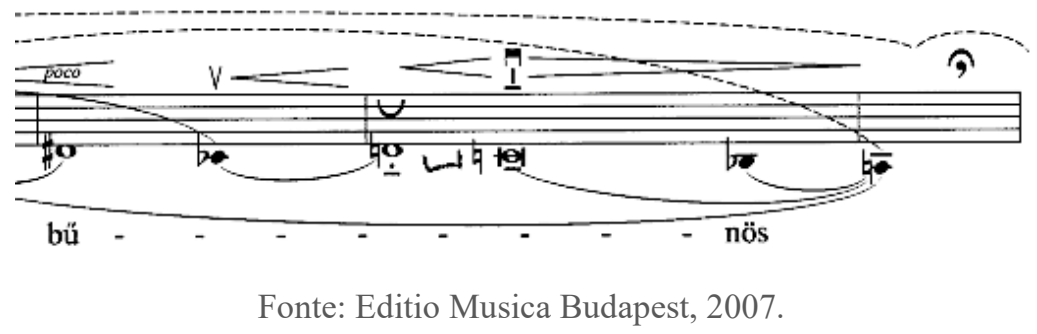

Tão importantes quanto os fonemas silábicos, contudo, são os silêncios. Dentro da estratégia proporcional de notação, a tipologia de pausas também é ampla, como mostra a bula de seus Játekok (Fig. 3), única peça do catálogo de Kurtág com um guia de notações mais preciso:

Figura 3 - György Kurtág, Bula dos Játekok.

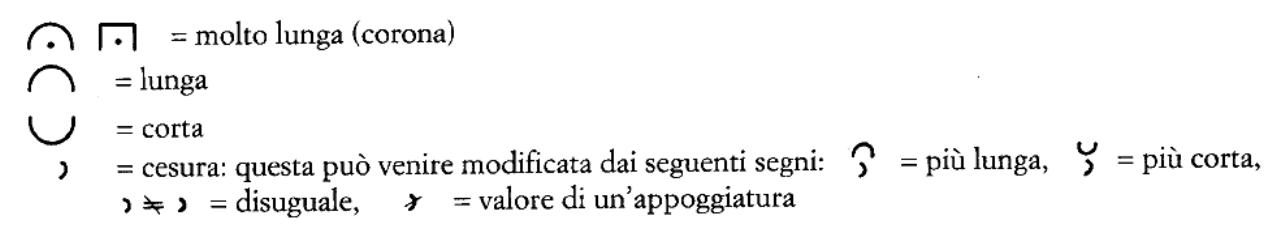

Fonte: Kurtág, 1991.

Porém, se a lista de pausas já é grande, deve-se levar em conta também os dois níveis de ligaduras que conectam e separam notas, acrescidas de acentos, tenutos e staccatos, que além de ataques, denotam também a resolução do envelope sonoro de cada articulação. Sendo assim, a dicção musical da peça se evidencia como sua grande questão interpretativa.

De certa forma, a notação de Kurtág demonstra a tentativa de um compositor (performer?) de recuperar a prática comum perdida de uma articulação performativa. Dos poucos vestígios dessa prática que restam, um dos mais valiosos sem dúvida é do método de flauta de Atys (1715-1784), Clef Facile et Méthodique, que adotava a pontuação da escrita verbal para ensinar a condução fraseológica (Fig. 4): 


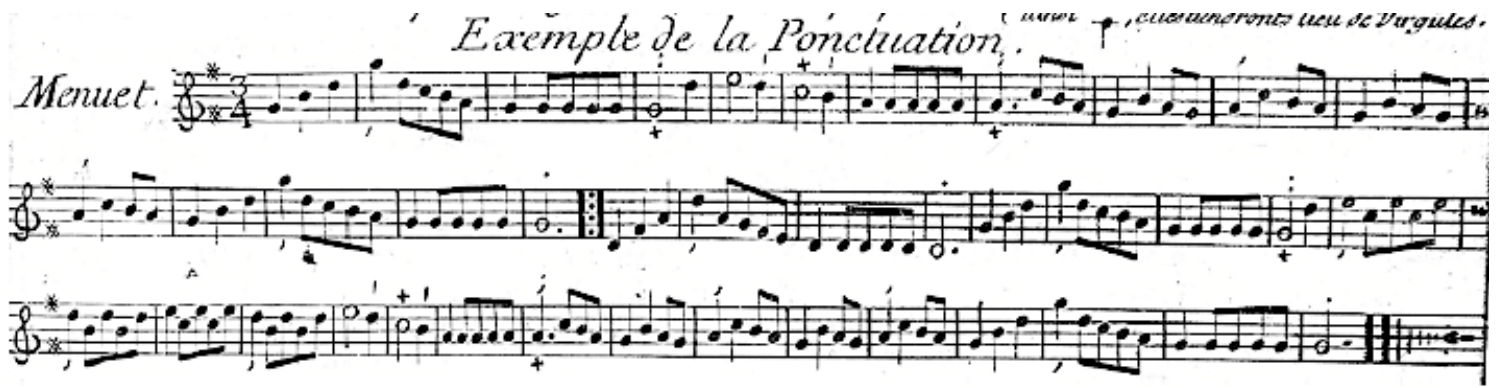

Fonte: Lyungar-Chapelon, 2015, p. 19.

Este é um cerne interpretativo que insere a performatividade do discurso como elemento essencial para a compreensão do sentido da pontuação, tanto no texto verbal quanto, em nosso caso, no texto musical. Como propõe Peter Szendy em sua "Estigmatologia" - o estudo da pontuação - o conhecimento sobre as regras gramaticais acerca desse dispositivo sintático pouco ensina sobre seu uso efetivo em um idioma, quanto mais quando se trata da música (SZENDY, 2018, p. 4). Ao recordar as críticas de Nietzsche às inovações terminológicas de seu amigo Hugo Riemann em sua teoria da frase musical, notando que teria sido melhor manter a ideia de frase dentro do domínio anterior da retórica, aliada à pontuação e à pronunciação, Szendy retoma a conclusão do filósofo: a rítmica musical que ignora a pontuação cabível à pronunciação do texto leva à perda da humanidade da própria música (SZENDY, 2018, p. 41). Por essa razão, Kurtág na verdade busca subsídios em uma música pré-moderna para lidar com os efeitos da objetificação da nota que herdou do serialismo e que por estar introjetada na formação musical atual, também exige um esforço adicional do performer para recuperar a própria humanidade na música tocada.

\section{B. A. Zimmermann, Estudo n. 3}

Se no primeiro exemplo a falta de uma direcionalidade tonal impede a identificação de uma frase, cabendo a outras relações com o texto a constituição de uma linha tão longa, no próximo exemplo (Fig. 5) reside na energia do movimento o fio da continuidade musical em suas irregularidades e ranhuras temporais. Isso fora mais detalhados em uma análise feita da Sonata de B. A. Zimmermann (TEIXEIRA; 
FERRAZ, 2017), mas o terceiro estudo de um conjunto de quatro, escritos pelo mesmo compositor, é um exemplo importante que esclarece a compreensão de que não apenas a alternância entre quiálteras de cinco e seis notas afere um senso de ondulação da subdivisão, mas o adensamento da configuração interna por meio da mudança entre modos de ataque distintos, a inclusão de mais ou menos notas, constituindo por vezes acordes, e mesmo a demanda por arcadas, cordas ou articulações específicas, tudo isso feito na região do talão e o mais rápido e forte possível. Tais condições exigem que o instrumentista esteja no limite de sua energia, tornando tais irregularidades não só inevitáveis, mas desejáveis, como revelado pelo compositor em seu influente ensaio Interval und Zeit (ZIMMERMANN, 2010).

Figura 5 - B. A. Zimmermann, 4 Pequenos estudos, n. 3.
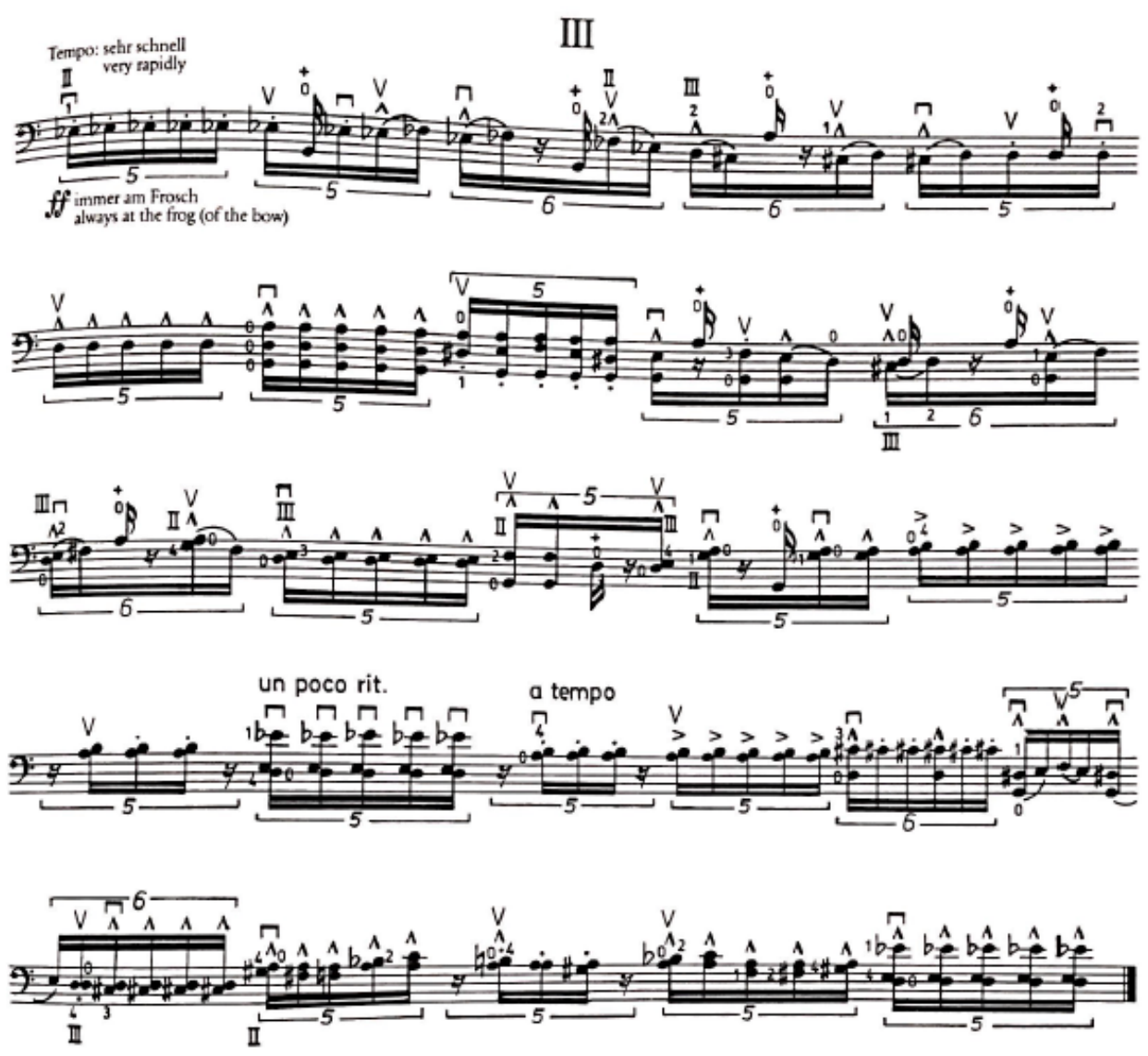

Fonte: Palm, 1985, p. 59. 
A peça se insere em uma tradição típica do virtuosismo instrumental pósromântico de peças que consistem em sequências praticamente ininterruptas de notas rápidas, tal qual o Moto Perpétuo de Paganini ou o quarto movimento Rasendes Zeitmaß da Sonata para viola solo op. 25 de Hindemith, que seria retomado na Sequenza VI de Berio. No entanto, se a escuta muitas vezes capta apenas um fluxo incansável e quase maquínico, para o performer, possuir alguma direção para esse fluxo é essencial para a própria condução do discurso, mesmo que isso não implique em qualquer quebra sonora. Curiosamente, ao se examinar com mais cuidado, nota-se que esse tipo de virtuosismo não é exclusividade da performance instrumental. Na própria prática popular do repente e suas rápidas improvisações, a velocidade é um componente central do efeito expressivo do gênero, mesmo que comprometendo a inteligibilidade do texto. De fato, na própria fala, a velocidade e a assimetria sintática são componentes distintivos, quase que de estilo, poderia-se dizer.

Foi justamente esse traço de musicalidade da fala coloquial que tanto interessou a Guimarães Rosa e que o escritor captou com inigualável técnica. Em sua prosa, ele interpenetra imensos blocos semânticos, estendendo não apenas o limite temporal da frase, mas conectando discursos de forma a se integrarem em um fluxo único e assimétrico. Como comenta Nilce Sant'Anna Martins, autora do Léxico de Guimarães Rosa, “as palavras têm canto e plumagem”. Sendo assim, quanto o modelo da fala é frutífero à música que a própria música já não tenha sido à fala, como lembra a professora Nilce, “considerando que a língua é também música” (MARTINS, 2014, p. 235, 237). Nesse sentido, seria possível se sugerir uma análise musical do próprio texto, versificando sua pontuação como notação de oralidade, tal qual percebeu Kurtág, irrompendo um fluxo de ideias que se articula pouco a pouco:

\footnotetext{
- NONADA.

TIROS QUE O SENHOR ouviu foram de briga de homem não, Deus esteja.

Alvejei mira em árvores no quintal, no baixo do córrego.

Por meu acerto.

Todo dia isso faço, gosto; desde mal em minha mocidade.

Daí, vieram me chamar.

Causa dum bezerro: um bezerro branco, erroso, os olhos de nem ser - se viu -; e com máscara de cachorro.

Me disseram; eu não quis avistar.

Mesmo que, por defeito como nasceu, arrebitado de beiços, esse figurava rindo feito pessoa.
} 
Cara de gente, cara de cão: determinaram - era o demo.

Povo prascóvio.

Mataram.

Dono dele nem sei quem for.

Vieram emprestar minhas armas, cedi.

Não tenho abusões.

O senhor ri certas risadas...

Olhe: quando é tiro de verdade, primeiro a cachorrada pega a latir, instantaneamente - depois, então, se vai ver se deu mortos.

O senhor tolere, isto é o sertão.

Uns querem que não seja: que situado sertão é por os campos-gerais a fora a dentro, eles dizem, fim de rumo, terras altas, demais do Urucuia. Toleima.

Para os de Corinto e do Curvelo, então, o aqui não é dito sertão?

Ah, que tem maior!

Lugar sertão se divulga: é onde os pastos carecem de fechos; onde um pode torar dez, quinze léguas, sem topar com casa de morador; e onde criminoso vive seu cristo-jesus, arredado do arrocho de autoridade.

O Urucuia vem dos montões oestes.

Mas, hoje, que na beira dele, tudo dá - fazendões de fazendas almargem de vargens de bom render, as vazantes; culturas que vão de mata em mata, madeiras de grossura, até ainda virgens dessas lá há.

O gerais corre em volta.

Esses gerais são sem tamanho.

Enfim, cada um o que quer aprova, o senhor sabe: pão ou pães, é questão de opiniães...

O sertão está em toda a parte.

(ROSA, 1994, p. 2-3, primeiro parágrafo)

Uma tentativa aproximada como essa já demonstra que o atributo de tal retórica é exatamente a assimetria: de sílabas, de ideias, de agenciamentos, de campos semânticos, de sonoridades; e tudo isso em um fluxo ininterrupto extremamente veloz. Um redemoinho expressivo onde cada linha deixa de ser frase para ser gesto, carregando consigo a leitura justamente ao recuperar a oralidade da fala coloquial. A escrita tenta formalizar a informalidade da fala por meio de vírgulas, pontos, travessões, ponto e vírgula, dois pontos, reticências... mas é impossível se capturar a velocidade da linguagem no ato de ser feita. Versificações e pontuações nada mais são do que tentativas de se criar fluxos temporais múltiplos que se atualizarão como um fluxo único. Em uma homenagem a Cage (Fig. 6), Kurtág torna visível a assimetria dessa tentativa, que também é musical. 

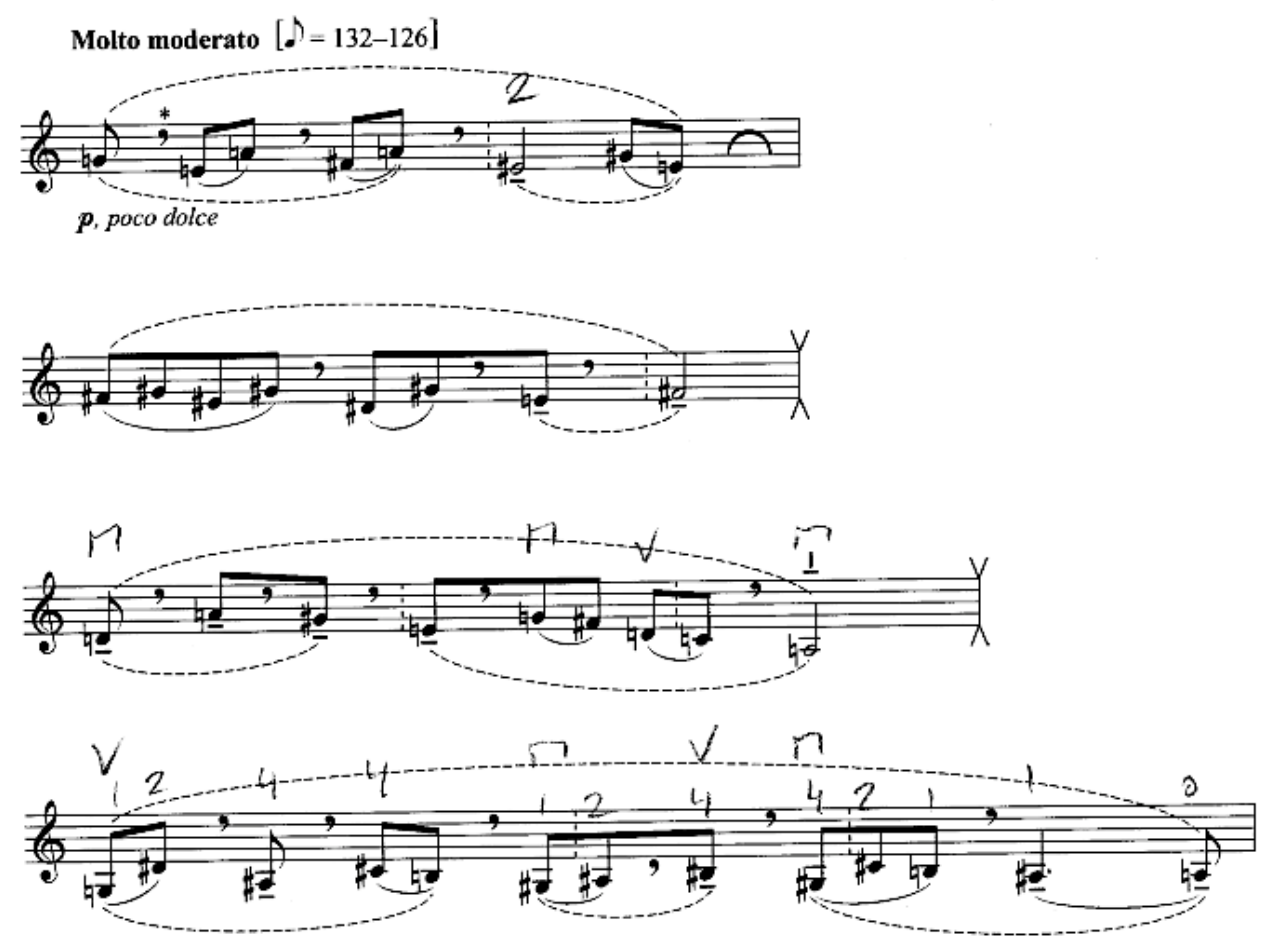

Fonte: Edition Musica Budapest, 1991.

Esse virtuosismo instrumental demonstra, assim como o virtuosismo da fala, um tipo de encantamento, um labirinto que a imprevisibilidade dessa aparente falta de um sentido gera. A mesma relação se faz presente em outros gêneros musicais populares, mantendo a conotação virtuosística da fala ou do canto em velocidade rápida, de modo a ocultar a inteligibilidade das palavras e frases sem problema algum. Um exemplo é este estilo do hip-hop dos Estados Unidos chamado chopper rap ou speed rap. Seu atributo distintivo está exatamente nos rápidos andamentos, fluxos ininterruptos e as variações rítmicas dentro do fluxo. Uma breve transcrição de um trecho (Fig. 7) demonstra a riqueza e complexidade desse discurso, onde os inícios de versos ficam por vezes deslocados ritmicamente dos tempos fortes.

Desse modo, é possível observar em um discurso musical vocal como esse a ausência de necessidade de simetria rítmica para a organização dos segmentos e que é justamente na dificuldade de dicção e, consequentemente, da compreensão, que está o interesse da escuta. Similarmente, em uma peça como o estudo de Zimmermann 
mencionado, deve-se buscar uma organização que não implique em segmentação rítmica, mas apenas em impulsos para novos fluxos sem qualquer interrupção.
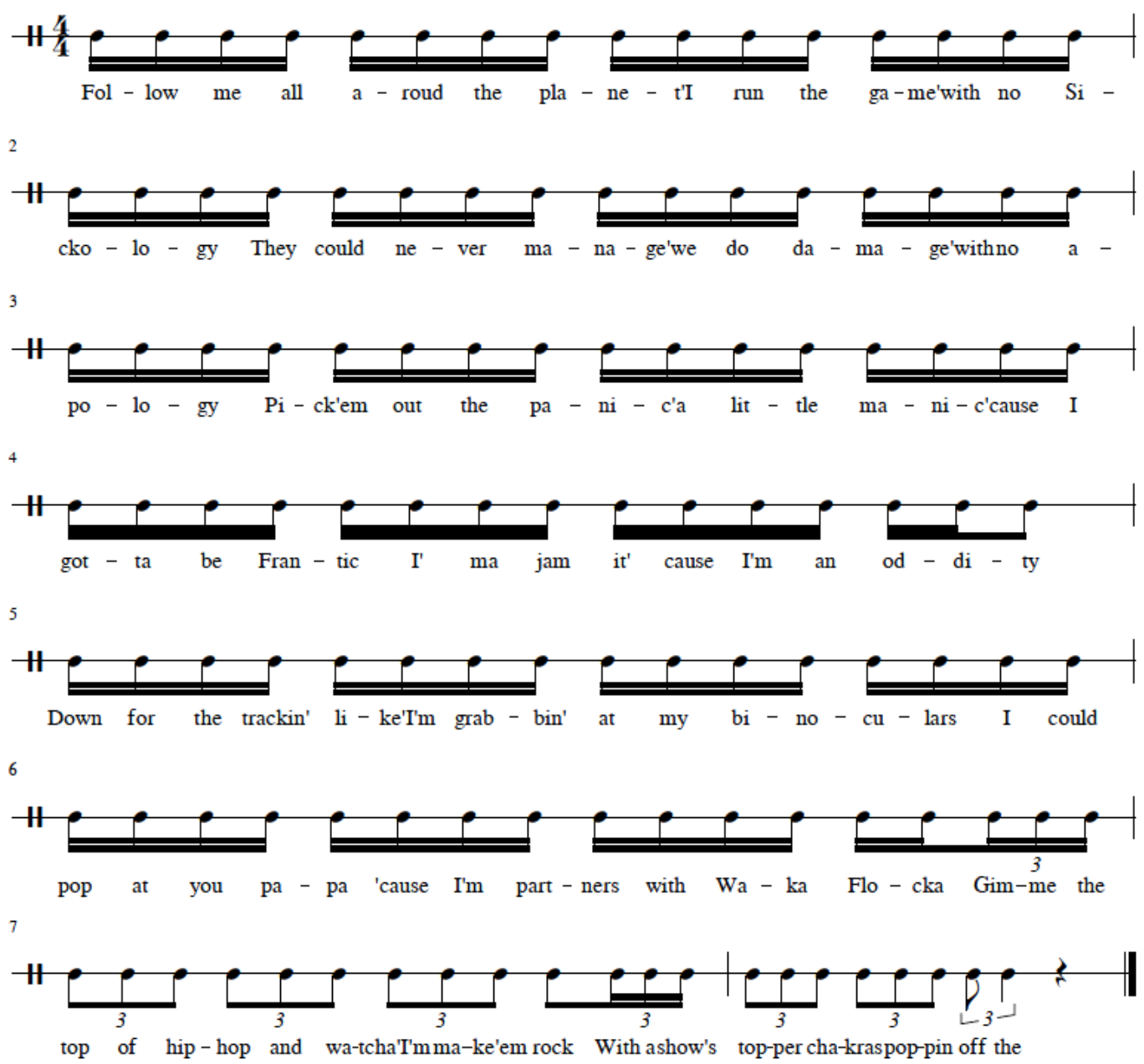

Fonte: Transcrição do autor.

\section{Silvio Ferraz, Partita-passagem}

A peça partita-passagem, escrita pelo compositor Silvo Ferraz como movimento intermediário entre sua mais antiga Partita 1 com uma nova Partita 3 
(FERRAZ, TEIXEIRA, 2019), foi concebida pelo compositor em poucos minutos, às vésperas de uma gravação realizada no Estúdio LAMUS, do Departamento de Música da USP, e foi estudada por este autor em outros poucos minutos, tendo sido gravada no quarto take do registro que será apresentado adiante. O que despertou o interesse em sua lógica melódica foi a ausência de qualquer segmentação durante toda a peça e, ao mesmo tempo, alguma coisa que tenha tornado o quarto take daquela seção tão claramente mais adequado em relação aos anteriores, de modo que ao término dele, parecia óbvio a ambos que aquela era a performance objetivada ${ }^{2}$.

No caso da partita-passagem (Fig. 8), esse mecanismo intuitivo poderia ser descrito na medida em que agencia o fluxo de energia em maiores ou menores intensidades, atravessando as linhas de maneira a manter uma continuidade única neste caso em específico, sem corte algum. Composicionalmente, as appoggiaturas são injetores de energia por natureza, mas reside especialmente nas notas longas o grande risco da peça no que tange à performance, por serem potenciais dissipadoras de energia, que resultam na interrupção de uma frase, se fossem entendidas como tais. Alguns elementos auxiliam na identificação desses locais mais arriscados e, ao mesmo tempo, com o potencial de exploração por parte do performer. Em todas as ocorrências de mínimas essa dificuldade surge, geralmente adotando a performance um certo tipo de interpenetração que movimenta a nota longa para uma sensação de término, deixando a continuidade por um fio, mas imediatamente conectando ao recomeço de uma próxima linha, outorgando interesse à escuta sem para isso perder sua energia e atenção ao permitir que algum corte aconteça. Em momentos de grande presença de mudanças de cordas, como na terceira linha, o fluxo corre o risco de se quebrar, porém é mantido pela reiteração de um Sol, que se transforma em um eixo de continuidade nesse momento. Essas reiterações, no entanto, fazem que ao chegar a quarta linha, seja muito difícil se manter o interesse em mais uma repetição do Sol. A rápida mudança do eixo para Lá bemol, que conduz a volta ao Sol, recupera a energia, dessa vez, no entanto, por uma memória de curtíssimo prazo formada de maneira imanente pelos compassos imediatamente anteriores.

\footnotetext{
${ }^{2}$ Gravação disponível em: https://youtu.be/Z5uNlvqfgpw?t=252. Acesso em: 23 mar. 2021.
} 
Figura 8 - Silvio Ferraz, Partita-passagem.

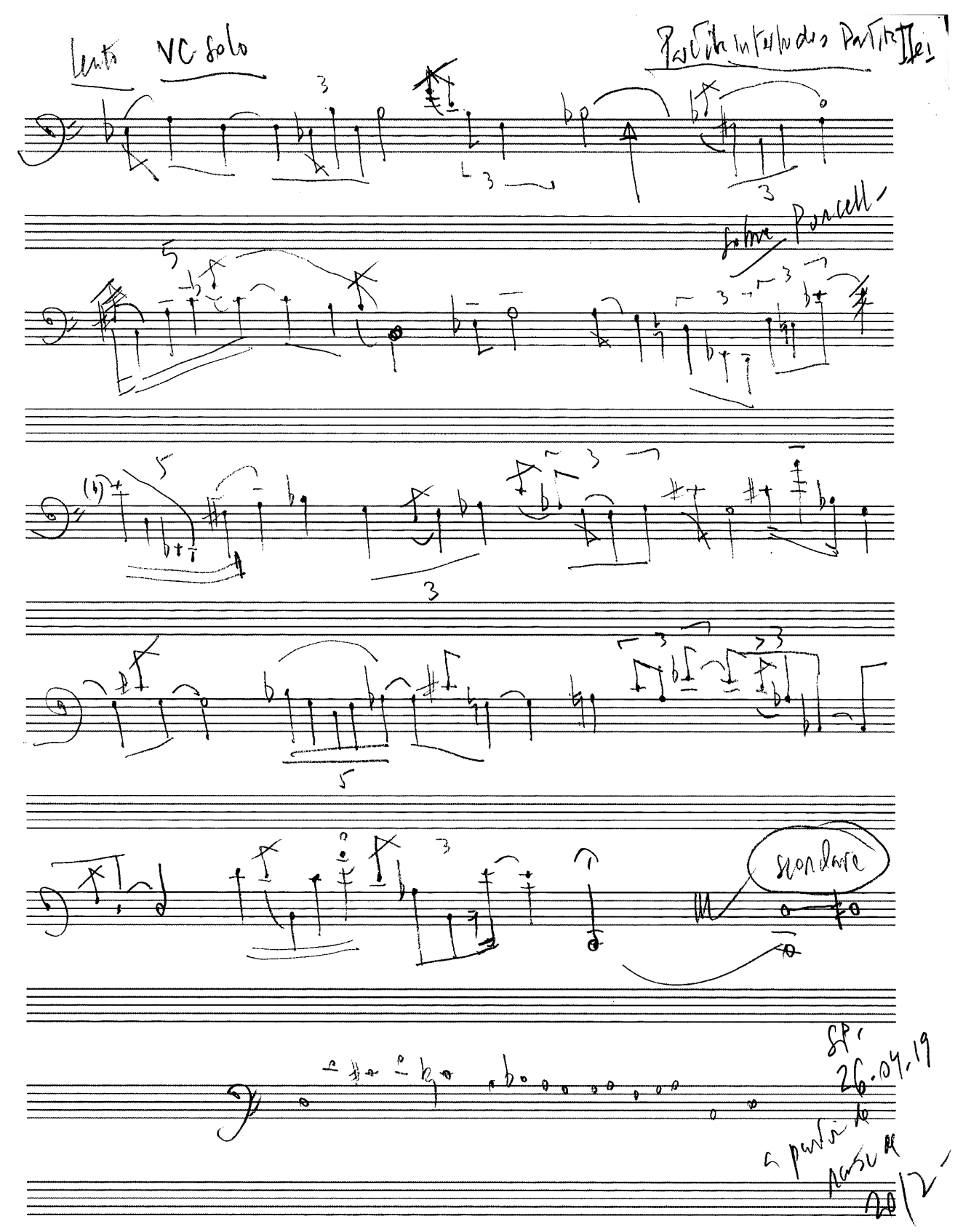

Em um trecho como esse não há frase ou qualquer tipo de segmentação. Apenas uma longa e implacável linha que se mantém viva pelos impulsos das appoggiaturas e das inflexões que o performer cria nas notas longas. Também não basta uma performance estática, que simplesmente toque as notas uma atrás da outra, pois a 
falta de direção leva a uma escuta monótona e sem sentido. Há de se pensar uma espécie de respiração contínua do arco que jamais se quebra e jamais abandona o som.

\section{Notas finais}

Os três exemplos demonstram, cada um à sua maneira, a ineficácia do paradigma da frase musical para explicar a construção melódica em uma parte relevante do repertório contemporâneo. Antes, são necessários outros tipos de agenciamento na sucessão de singularidades gestuais que permitam não apenas um agrupamento formal, mas, principalmente, uma articulação que permita a performance de tais estruturas. Esses agenciamentos não carecem necessariamente de uma nova teoria fraseológica, mas de novas imagens analógicas que permitam a transdução da energia simbólica da partitura em movimentos que, para tanto, precisarão de direções expressivas mais claras.

A analogia, contudo, parte do suposto que é parte da singularidade musical uma singularidade analítica, cabendo um esforço a cada caso de se entender sua própria realidade e atualidade musical. Torna-se necessário um pensamento analítico criativo e, em certa medida, nômade, se movimentando e se reconfigurando caso a caso, o que implicaria em um novo tipo de pedagogia musical que não prenda o estudante a modelos tão somente linguísticos. Em ser redesenhado, o paradigma da frase musical pode se beneficiar da performance e sua corporeidade como instrumentos de análise, evidenciando limites e possibilidades que a estrutura sozinha permanece inábil de concluir sozinha. Ainda que deva ser corporificado diferentemente caso a caso, os princípios aqui discutidos passam, pouco a pouco, a serem assimilados como linhas gerais que auxiliam em um ponto de partida mais efetivo para novos discursos. A retórica, nesse sentido, demonstra sua vitalidade na música instrumental, não como uma teoria determinista de figurações e afetos, mas principalmente como uma via de comunhão entre composição e performer em prol de um propósito expressivo a ser pronunciado pelo intérprete sobre o palco. 


\section{Referências}

ALBERA, Philippe. György Kurtág: Entretiens, textes, ecrits sur son oeuvre. Genebra: Contrechamps, 1990.

BARROS, Caio G. Teorias do agrupamento sonoro: propriedades e condições de existência de elementos sonoros temporalmente discrimináveis e o essencialismo na construção de conceitos da teoria musical. Dissertação (Mestrado) - Instituto de Artes, Universidade Estadual Paulista, 2013.

BONDS, Marc Ellis. Wordless Rhetoric. Cambridge: Harvard University Press, 1991.

DRABKIN, William; PFINGSTEN, Ingeborg. Satz. In: GROVE MUSIC ONLINE, 2001. Disponível em: https://doi.org/10.1093/gmo/9781561592630.article.24628. Acesso em: 26 abr. 2021.

FERRAZ, Silvio. Kairos: ponto de ruptura. Ouvirouver, Universidade Federal de Uberlândia, Uberlândia, v. 11, n. 1, p. 34-52, 2015. Disponível em: https://doi.org/10.14393/OUV16v11n1a2015-2. Acesso em: 26 abr. 2021.

FERRAZ, Silvio. Beckett e música: a composição do tempo. EUTOMIA, v. 20, p. 1-20, 2017.

FERRAZ, Silvio. Partita-passagem. São Paulo: [s.n.], 2019. 1 partitura manuscrita.

FERRAZ, Sílvio; TEIXEIRA, William. Partita 3, para violoncelo solo: preparação de performance depois das notas sobre o fluxo de energia. Art Research Journal, v. 6, n. 2, p. 1-28, 2019. Disponível em: https://doi.org/10.36025/arj.v6i2.17690. Acesso em: 26 abr. 2021.

KELLER, Herman. Phrasing and Articulation: A Contribution to a Rhetoric of Music. Tradução de Leigh Gerdine. New York: W. W. Norton \& Company, 1973.

KOCH, Heinrich Christoph. Versuch einer Anleitung zur Composition, 3 Bände. Rudolstadt und Leipzig, 1782.

KURTÁG, György. Játekok. v. 1. Milão: Ricordi, 1991.

KURTÁG, György. Az hit... Editio Musica Budapest, 2007.

KURTÁG, György. Hommage à John Cage. Editio Musica Budapest, 1991.

LERDAHL, Fred; JACKENDOFF, Ray. A Generative Theory of Tonal Music. Cambridge: MIT Press, 1983.

LJUNGAR-CHAPELON, Anders (Ed.). Atys: Six sonates en duo oeuvre IV, 1760: clef facile et méthodique oeuvre V, 1763 . (Flöjtisten vademecum = The flautists vademecum). Malmö: Lund University, Malmö Academy of Music, 2015.

MARTINS, Nilce S. Semântica e estilística: dimensões atuais do significado e do estilo. São Paulo: Pontes, 2014.

MENEZES, Flo. Berio e a Palavra. In: MENEZES, Flo (Org.). Berio: legado e atualidade. São Paulo: Editora UNESP, 2015. 
PALM, Siegfried. Pro Musica Nova: Studien zum spielen neuer Musik für Violoncello. Wiesbaden: Breitkopf \& Härtel, 1985.

RIEMANN, Hugo. Fraseo Musical. Barcelona: Editorial Labor, 1928.

SCHOENBERG, Arnold. Fundamentos da composição musical. 2. ed. São Paulo: Edusp, 1993.

SCLIAR, Esther. Fraseologia musical. Porto Alegre: Movimento, 1982.

SILVA, Rafael A. A obra coral de Gilberto Mendes e a poesia concreta do grupo Noigandres: uma análise multimidática. Dissertação (Mestrado), Escola de Comunicações e Artes, Universidade de São Paulo, São Paulo, 2014.

SZENDY, Peter. Musique et texte dans l'oeuvre de György Kurtág, In: ALBERA, Philippe (Ed.). György Kurtág. Genebra: Contrechamps, 1990. p. 266-284.

SZENDY, Peter. Of Stigmatology: pontuaction as experience. Tradução de Jan Plug. New York: Fordham University Press, 2018.

TEIXEIRA, William; FERRAZ, Sílvio. Uma nova retórica para uma nova música. In:

ENCONTRO INTERNACIONAL DE TEORIA E ANÁLISE MUSICAL, 3., 2013, São Paulo. Anais... São Paulo, Universidade de São Paulo, 2013, p. 346-351. Disponível em:

http://www2.eca.usp.br/etam/iiiencontro/files/comm_Silva_Ferraz_p346-351.pdf. Acesso em: 26 abr. 2021.

TEIXEIRA, William; FERRAZ, Sílvio. B.A. Zimmermann's Solo Cello Sonata, page 1, system 6: A Thick Description. In: ENCONTRO INTERNACIONAL DE TEORIA E ANÁLISE MUSICAL, 4., 2017, São Paulo. Anais... São Paulo, Universidade de São Paulo, 2017, p. 431442. Disponível em: http://www2.eca.usp.br/etam/ivencontro/EITAM4.pdf. Acesso em: 26 abr. 2021.

TEIXEIRA, William; NOGUEIRA, Marcos Pupo. A articulação musical no contexto da metamorfose da palavra cantada e sua influência na formação de agrupamentos fraseológicos a música instrumental. In: ENCONTRO INTERNACIONAL DE TEORIA E ANÁLISE MUSICAL, 2., 2011, São Paulo. Anais... São Paulo, Universidade Estadual Paulista, 2011. v. 1, p. 166-176.

TEIXEIRA, William; NOGUEIRA, Marcos Pupo. Frases, linhas, partes... fluxo de energia e a conexão melódica na performance musical. In: ENCONTRO INTERNACIONAL DE TEORIA E ANÁLISE MUSICAL, 5., 2019, Campinas. Anais... Campinas, Universidade Estadual de Campinas, 2019. p. 319-332. Disponível em: https://eitam5.nics.unicamp.br/wp-

content/uploads/2020/12/EITAM5-paper_23 TeixeiraW-pp 319-332.pdf. Acesso em: 26 abr. 2021.

TORRANCE, Alan. Analogy. In: VANHOOZER, Kevin (Org.). Dictionary for Theological Interpretation of the Bible. Grand Rapids: Baker, 2005.

WILSON, Rachel Beckles. To Say and/or to Be? Incongruence in Kurtág's "The Sayings of Peter Bornemisza", Op. 7. Music Analysis, v. 22, n. 3, p. 315-338, 2003.

ZIMMERMANN, Bernd Alois. Écrits. Editados por Philippe Albèra. Tradução de Marc-Ariel Friedemann. Genebra: Editions Contrechamps, 2010. 
Revista Música, v. 21 n. 1 - Dossiê Música em Quarentena (parte II);

Dossiê Encontro Internacional de Teoria e Análise Musical - 10 Anos

Universidade de São Paulo, julho de 2021

ISSN 2238-7625 